\title{
Strategies for the Development of Novel Tumor Targeting Technetium and Rhenium Radiopharmaceuticals
}

\author{
Thomas Mindta ${ }^{a}$ Harriet Struthers ${ }^{\mathrm{b}}$, Elisa Garcia-Garayoa ${ }^{\mathrm{b}}$, Dominique Desbouis ${ }^{\mathrm{b}}$, and \\ Roger Schibli ${ }^{\star a b}$
}

\begin{abstract}
The labeling of tumor targeting biomolecules with the $\gamma$-emitting nuclide Tc-99m and the $\beta$-emitting nuclides Re-186/188 is an attractive option for non-invasive diagnosis and therapy of cancerous diseases. Issues such as availability, low costs, high specific activity and suitable decay properties are responsible for the prominent role of Tc-99m and Re-188. In addition Tc-99m and Re-186/188 represent one of the few 'matched-pairs' of diagnostic and therapeutic radionuclides with identical or very similar chemical characteristics. Basic chemistry for both elements has made tremendous progress in the past. A variety of established Tc/Re-metal cores, metal chelating systems and reliable labeling methods are available today. However, despite enormous research efforts, the new generation of specific Tc/Re-radiopharmaceuticals is far from their introduction into routine clinical practice. The reasons are manifold and, from a scientific point of view, not always justified. Functionalization and Tc/Re-labeling of promising, small (tumor) targeting molecules without compromising their biological affinity or fate is a frequent problem. In this article, promising pharmacological and chemical approaches necessary for the development of a novel generation of Tc/Re radiopharmaceuticals are described.
\end{abstract}

Keywords: Radiopharmaceuticals · Rhenium - SPECT · Technetium - Tumor Targeting

\section{Background and Introduction}

Cancer accounts for approximately $25 \%$ of deaths in the EU and similar numbers are reported for the US and other developed countries. ${ }^{[1]}$ Studies of the EU Commission revealed that at the time patients are first diagnosed with cancer, $40 \%$ have already developed metastatic lesions, which often results in poor prognosis. Thus, the development of new strategies for early diagnosis and therapy of (disseminated) tumors is of paramount interest for effective patient management. Systemic application of tumor-seeking molecules labeled with diagnostic radionuclides $(\gamma$-emitters for single photon emission computed to-

${ }^{\star}$ Correspondence: Prof. Dr. R. Schibliab

Tel.: + 41446337464

Fax: + 41563102849

E-Mail: roger.schibli@pharma.ethz.ch

alnstitute of Pharmaceutical Sciences

ETHZ Hönggerberg

$\mathrm{HCl} \mathrm{H} 425$

$\mathrm{CH}-8093$ Zürich

${ }^{b}$ Center for Radiopharmaceutical Science

Paul Scherrer Institute

$\mathrm{CH}-5232$ Villigen PSI mography (SPECT) or $\beta^{+}$-emitters for position emission tomography (PET)) is currently one of the most sensitive methodologies for the non-invasive detection of cancer in vivo. SPECT and PET enable the detection of lesions of a few millimeters to centimeters at micro- to nanomolar (or even lower) concentrations of the tracer because only a few $\mathrm{MBq}$ of a short-lived radionuclide is necessary (Fig. 1). Systemic delivery of molecules radiolabeled with particle-emitting radionuclides such as $\alpha$-, $\beta^{-}$- and Auger-emitters may allow destruction of disseminated tumors, which cannot be reached efficiently by other modalities. Thus, the formulation of radioactive drugs (radiopharmaceuticals, radioconjugates) that selectively target a specific molecular site in the human body while minimizing any uptake in non-targeted organs and tissues, has been the challenge and the focus of radiopharmaceutical development in the recent past. To achieve this goal a thorough investigation of the molecular target, the targeting molecule and its metabolism and the labeling site of the molecule is pivotal. Equally important is the choice of an appropriate radionuclide and the chemical methods to incorporate it into a targeting molecule. Impressive advances have been made in the case of specific antibodies and peptides against tumor-associated cell surface proteins. ${ }^{[2,3]}$

Many isotopes with decay properties suitable for diagnosis and particularly therapy are transition metal elements or possess a metallic character. Thus, to label targeting

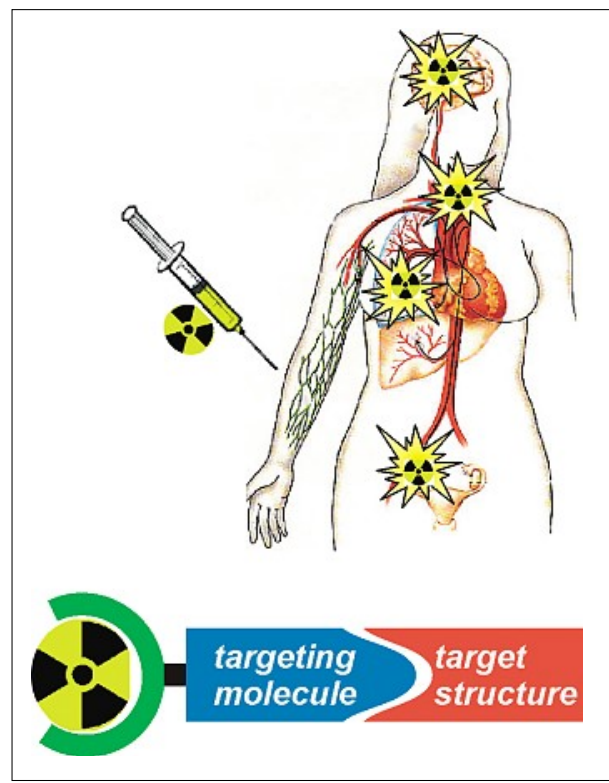

Fig. 1. Principle of specific tumor targeting with systemically applied, tumor affinity radiopharmaceuticals (radioconjugate) 
molecules with such radionuclides they have to be functionalized with a so-called bifunctional chelating agent (BFCA) capable of stabilizing the metal center and tightly connecting it to the biological vector. Thereby, the biological activity and affinity of the biologically active molecule should not be compromised or altered. This is a challenging endeavor and many chemical, physical and pharmacological parameters have to be carefully evaluated and optimized.

\section{The Prominent Status of Technetium and Rhenium in Radiopharmacy}

The most interesting and widely used isotope for diagnosis is technetium- $99 \mathrm{~m} \mathrm{(m}$ $=$ metastable). Several reasons are responsible for the prominent role of Tc-99m:

i) The physical decay properties are almost ideal for diagnosis (Fig. 2). Its half-life of six hours is short enough to enable the administration of low doses for obtaining good quality images. The energy of the $\gamma$-emission of $140 \mathrm{keV}$ is sufficient to penetrate the human tissue without much attenuation and thus can be externally monitored by a $\gamma$-camera.

ii) Tc-99m is readily available at low costs compared to other radionuclides. This is possible due to a Mo-99/Tc-99m-isotope generator system from which Tc-99m (as $\mathrm{Na}\left[{ }^{99 \mathrm{~m}} \mathrm{Tc}^{\mathrm{VII}} \mathrm{O}_{4}\right]$ ) can be periodically eluted with physiological saline, in high specific activity and in excellent chemical and biological purity. This constant, reliable and economic supply cannot be guarantied for any other medically relevant radionuclide at the moment.

A similar situation is encountered for Re-188:

i) $\operatorname{Re}-188$ decays under emission of $\beta^{-}$and $\gamma$-radiation $\left(\mathrm{E}_{\beta}\right.$ average $=0.8 \mathrm{MeV}$ (probability 70\%); $\mathrm{E}_{\gamma}=155 \mathrm{keV}$ (probability $15 \%$ )) with a half-life of 17 hours (Fig. 2). The $\beta$-particle emission is suitable for radionuclide therapy, whereas the co-emitted $\gamma$-radiation allows in vivo tracking of the radiolabeled biomolecules and dosimetry calculation of the radiotracer.

ii) Re-188 can also be obtained as perrhenate $\mathrm{Na}\left[{ }^{188} \mathrm{Re}^{\mathrm{VII}} \mathrm{O}_{4}\right.$ ] via a W-188/Re-188 isotope generator in analogy to the system for Tc-99m.

Re-186 is a reactor-produced isotope suitable for radionuclide therapy $\left(\mathrm{T}_{1 / 2}=3.7\right.$ $\mathrm{d})$. It is a $\beta$-emitting radionuclide of moderate energy $\left(\mathrm{E}_{\beta}\right.$ average $=0.36 \mathrm{MeV}$ (probability 70\%)) and it possesses a low-abundance $\gamma$-emission at $137 \mathrm{keV}$ (probability 9\%).

Apart from the good physical decay properties of these isotopes the chemical

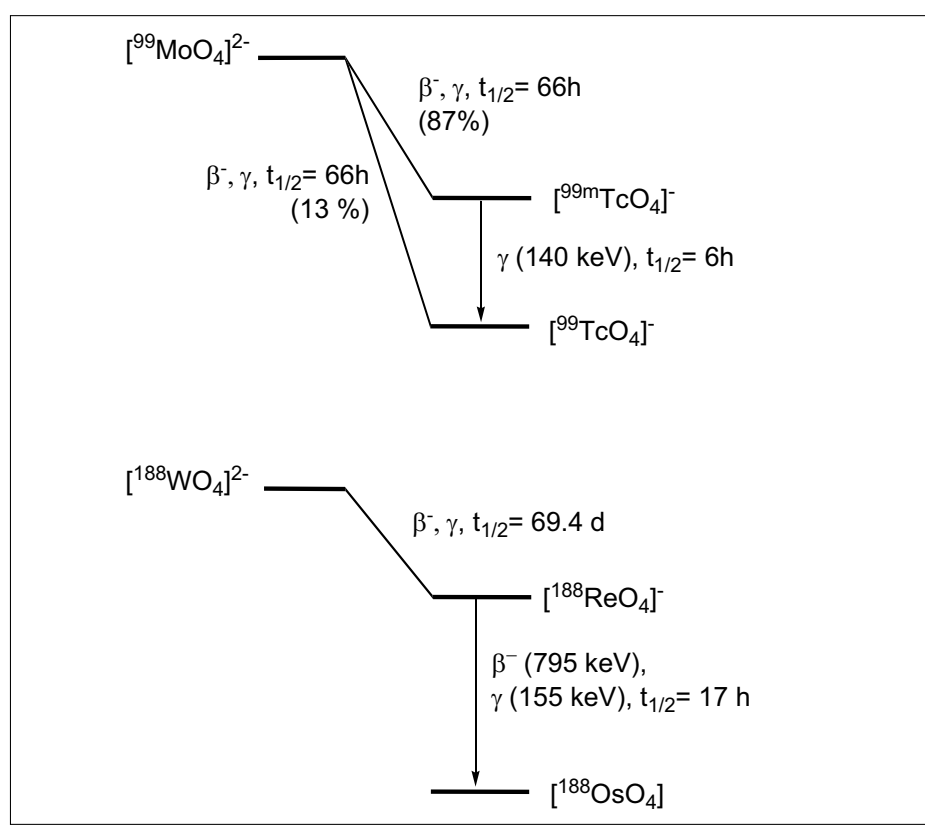

Fig. 2. Physical decay schemes of Mo-99/ Tc-99m and W-188/ $\mathrm{Re}-188$. In the radionuclide generators $\left[{ }^{99} \mathrm{MoO}_{4}\right]^{2-}$ or $\left[{ }^{188} \mathrm{WO}_{4}\right]^{2-}$ are stably absorbed on alumina columns from which steadily produced $\left[{ }^{99 \mathrm{~m}_{\mathrm{TCO}}}\right]^{-}$and $\left[{ }^{188} \mathrm{ReO}_{4}\right]^{-}$can be eluted with physiological saline.

similarity of technetium and rhenium is an important and appealing feature for diagnostic and therapeutic radiopharmacy. The elements share similar physico-chemical and chemical properties as a consequence of the lanthanide contraction. Ideally the chemistry developed for technetium can be transferred to rhenium and vice versa, which gives rise to a diagnostic and therapeutic 'matched-pair' constellation, otherwise rarely found in radiopharmacy.

\section{Strategies for Targeted Technetium and Rhenium Radiopharmaceuticals}

The emphasis of technetium- and rhenium-based agents has shifted in the recent past from perfusion agents to (receptor-) specific, targeted radioconjugates. As mentioned in the introduction, this entails the functionalization of a biological vector with a BFCA, which is able to:

i) Stabilize the metal under challenging in vivo conditions. Disconnection of the (particle emitting) radionuclide from the biological vector in vivo (e.g. via ligand exchange or oxidation of the Tc/Re center) could lead to an uncontrollable biodistribution of radioactivity and potentially to damage of healthy tissue. Frequently, the lower in vivo stability is a major drawback of Re-188-radiopharmaceuticals.

ii) Complex efficiently the metal center at low ligand concentration in order to obtain high specific activities of the corresponding tracer.

iii) Produce the radiotracer in high yields (generally $>95 \%$ ), as a single species and ready for injection without further purification steps.

iv) Preferably enable the corresponding complexes or bioconjugates to be pre- pared via a simple one-pot, one-step kit formulation in aqueous media. Thereby, the reaction conditions should be moderate and comply with the targeting molecule.

Due to the rich coordination chemistry of Tc and Re several metal cores are available nowadays for the radiolabeling of biomolecules (Fig. 3). In all instances, the corresponding permetallate must be reduced before complex formation can occur. A sheer infinite number of BFCA for Tc and Re have been developed and tested for the individual metal cores. ${ }^{[9,10]}$ Most of these BFCAs have also been optimized and screened for the efficient formation of $\mathrm{Tc} / \mathrm{Re}$ complexes at low ligand concentration. This becomes particularly important in case of receptor targeting biomolecules because receptor saturation with excess of unlabeled compound can be detrimental.[11]

The different metal cores and chelating systems enable the structural modification of a specific radioconjugate and, more importantly, allow the subtle modulation of its physico-chemical parameters such as hydrophilicity/lipophilicity and overall charge. Such fine-tuning can have a decisive impact on the targeting capacity of the bioconjugate or the rate and route of excretion. ${ }^{[12,13]} \mathrm{Hy}$ drophilic chelating moieties facilitate the clearance of the radiotracer from the blood pool and a fast excretion of radioactivity (including the radioactive metabolites) via the urinary tract with low retention of the radioactivity in the liver and the kidney. ${ }^{[14]}$ This is an important issue particularly for radionuclide therapy, since uptake and retention of radioactivity in the kidneys, liver and the bone marrow frequently limit the applicable dose. Another issue is the overall size of the technetium or rhenium complex in comparison with the targeting molecule. It is a 

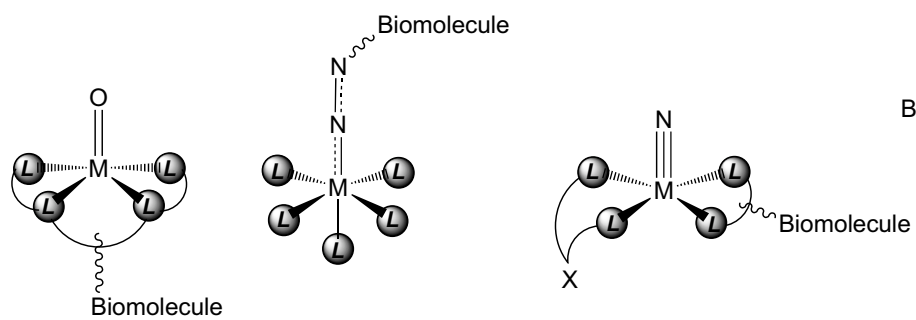

Biomolecule

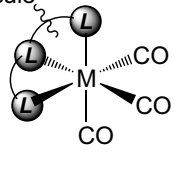

I

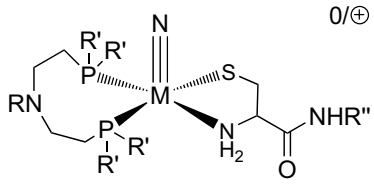

$0 / \oplus$
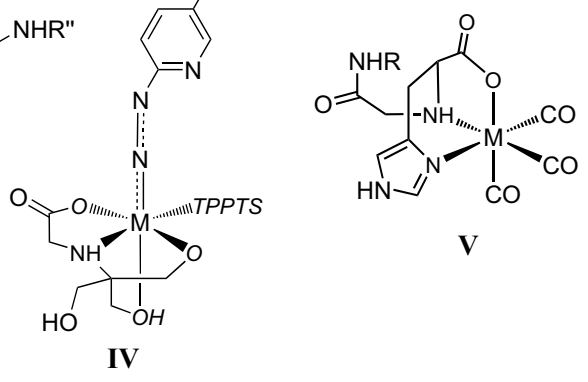

III

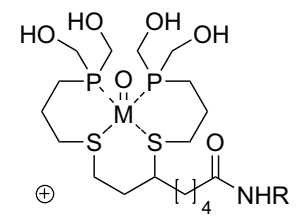

II

$\mathrm{NHR}$
Fig. 3. General structure of Tc/Re-cores used for labeling of biomolecules; (I) Tc/Re(v)-oxo complexes with tetradentate N/S-; ${ }^{[4]}$ (II) S/P-chelators; ${ }^{[5]}$ (III) HYNIC-system (hydrazino nicotinitc acid) with co-ligands TPPTS (trisodium triphenylphosphine-3,3',3' '-trisulfonate); [6] (IV) Tc/Re(V)-nitrido complexes; [7] (V) and organometallic Tc/Re(I)-tricarbonyl complexes with tridentate chelator. ${ }^{[8]}$

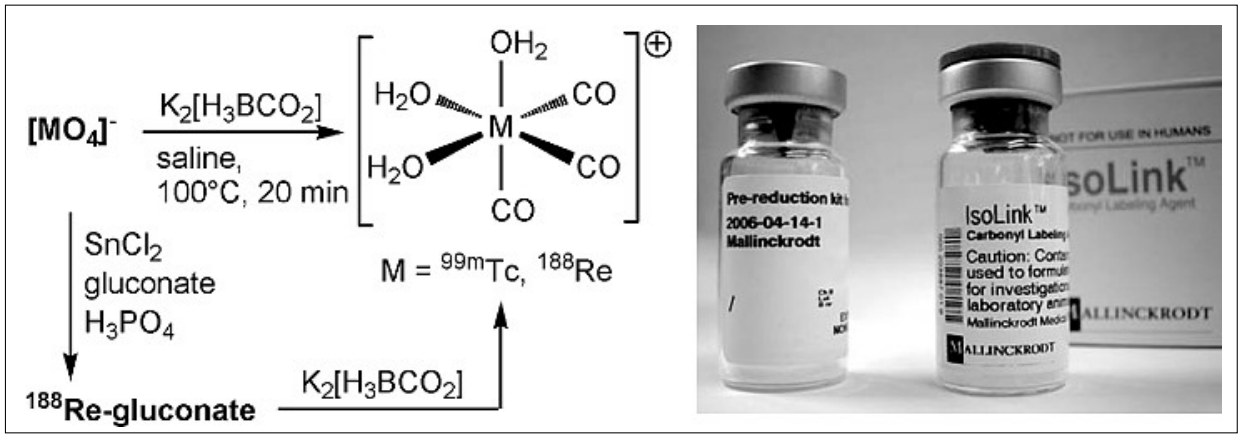

Fig. 4. Kit-formulation (one-step for Tc-99m and two-step for Re-188) for the synthesis of the organometallic precursors $\left[\mathrm{M}\left(\mathrm{OH}_{2}\right)_{3}(\mathrm{CO})_{3}\right]^{+}(\mathrm{M}=\mathrm{Tc}-99 \mathrm{~m}, \mathrm{Re}-188)$

common assumption that the smaller the Tc/ Re complex is, the higher the chance is that the biological activity of the radioconjugate will not be altered. This becomes a vital aspect particularly with target structures, which have a low tolerance for structural modification of the targeting molecule (vide infra). For the reasons mentioned above, water-soluble and water-stable Tc/Re-precursors with substitution-labile coordination sites have been proposed for the effective coupling to biomolecules under mild reaction conditions. One example is the tetra/penta-coordinated nitrido precursor with two coordination sites, which can readily be exchanged by bidentate chelating systems attached to e.g. ligands for CNS, or vitamins. ${ }^{[7,15-17]}$ Another precursor, with which our group has worked extensively, is the organometallic precursor $\left[\mathrm{M}\left(\mathrm{H}_{2} \mathrm{O}\right)_{3}(\mathrm{CO})_{3}\right]^{+}(\mathrm{M}=$ Tc-99m, Re-188) which has three tightly coordinated $\mathrm{CO}$ ligands and three water molecules, the latter of which can be readily substituted. ${ }^{[18,19]}$ The low-spin $\mathrm{d}^{6}$ configuration renders the metal center (and thus the complexes) very inert. Octahedral complexes with the $\mathrm{M}(\mathrm{CO})_{3}{ }^{+}$ core are generally smaller than octahedral or square-pyramidal complexes of technetium and rhenium in higher oxidation states as well as macrocyclic complexes of other (radio)metals e.g. with DOTA $(1,4,7,10$-tetraazacyclododecane-N,N',N",N"'-tetraacetic acid). Kit formulations for the preparation of $\left[{ }^{*} \mathrm{M}\left(\mathrm{H}_{2} \mathrm{O}\right)_{3}(\mathrm{CO})_{3}\right]+(* \mathrm{M}=\mathrm{Tc}-99 \mathrm{~m}$, Re-188) have been developed.[19,20] The preparation of $\left[{ }^{188} \mathrm{Re}\left(\mathrm{H}_{2} \mathrm{O}\right)_{3}(\mathrm{CO})_{3}\right]^{+}$needs a pre-reduction step, whereas the Tc-99m analog can be synthesized in one step directly from $\left[{ }^{99} \mathrm{mcO}_{4}\right]^{-}$(Fig. 4). Organometallic Tc$99 \mathrm{~m} / \mathrm{Re}-188$ complexes coordinated with tridentate chelating systems reveal good stability when challenged in human plasma or with excess cysteine, histidine or glutathione. ${ }^{[21,22]}$

\section{Tumor Targeting with Small Tc-99m/Re-188-radiolabled Molecules}

In recent years, several groups have become interested in the use of small Tc- $99 \mathrm{~m} /$ Re-188-radiolabled molecules essential for cell proliferation such as vitamins, ${ }^{[23-25]}$ nucleosides, ${ }^{[26-29]}$ carbohydrates ${ }^{[30,31]}$ and amino acids. ${ }^{[32]}$ However, this field is largely dominated by PET. For economic and logistic reasons it would be of paramount interest to develop the corresponding analogs for SPECT. In the following section, we would like to report on our strategies and recent progresses in an effort to develop novel, small-molecular radiotracers based on Tc-99m and Re-186/188.

Vitamin B9, folic acid (FA) and other folates are critical cofactors in a number of biochemical reactions, characterized by the transfer of a one-carbon group. These reactions are crucial for amino acid metabolism and de novo nucleotide synthesis and therefore important for cell survival and proliferation. It is thus not surprising that the folate receptor $(\alpha-F R$, a high-affinity membrane-anchored protein; $\mathrm{K}_{\mathrm{D}}$ for $\mathrm{FA}=$ $0.1-1 \mathrm{nM}$ ) is overexpressed on a wide variety of human tumors including ovarian, endometrial, breast, lung, renal as well as colon cancer. ${ }^{[33,34]}$ In normal tissue, the $\alpha$-FR is expressed only in the kidneys, the choroid plexus, the lungs and the placenta. The tumor-related expression of $\alpha$-FR makes FA an effective molecular 'Trojan horse' for the specific delivery of diagnostic and therapeutic probes into tumor cells. ${ }^{[35,36]} \mathrm{We}$ have recently synthesized novel organometallic Tc-99m/Re-188-folate derivatives (Fig. 5). ${ }^{[23,37]}$ With extensive pre-clinical in vivo studies including combined small animal SPECT and computed tomography (CT), we were able to show that specific tumor targeting is possible with such tracers. In mice bearing FR-positive tumor xenografts we have revealed almost identical pharmacokinetics for both Tc-99m and the isostructural Re-188 folate. ${ }^{[38]}$

We have also demonstrated that coapplication of chemotherapeutics (e.g. the antifolate Pemetrexed/Alimta $\left.{ }^{\mathrm{TM}}\right)$ reduced the FR-mediated (but unwanted) uptake of our radiofolates in normal renal tissue to an extent that potential radionuclide therapy can be envisaged (Fig. 5). ${ }^{[39]}$ This opens also opportunities for new combination therapies (chemo- and radionuclide therapy using Re-188 folates) for the treatment of FR-positive tumors in the future.

A second target of interest in our group is human thymidine kinase 1 (hTK1). It is well documented that the level of hTK1 is elevated in a number of rapidly proliferating and malignant cells. ${ }^{[40-43]}$ Thus, hTK1 is suitable for non-invasive imaging and therapy using non-radioactive and radioactively 


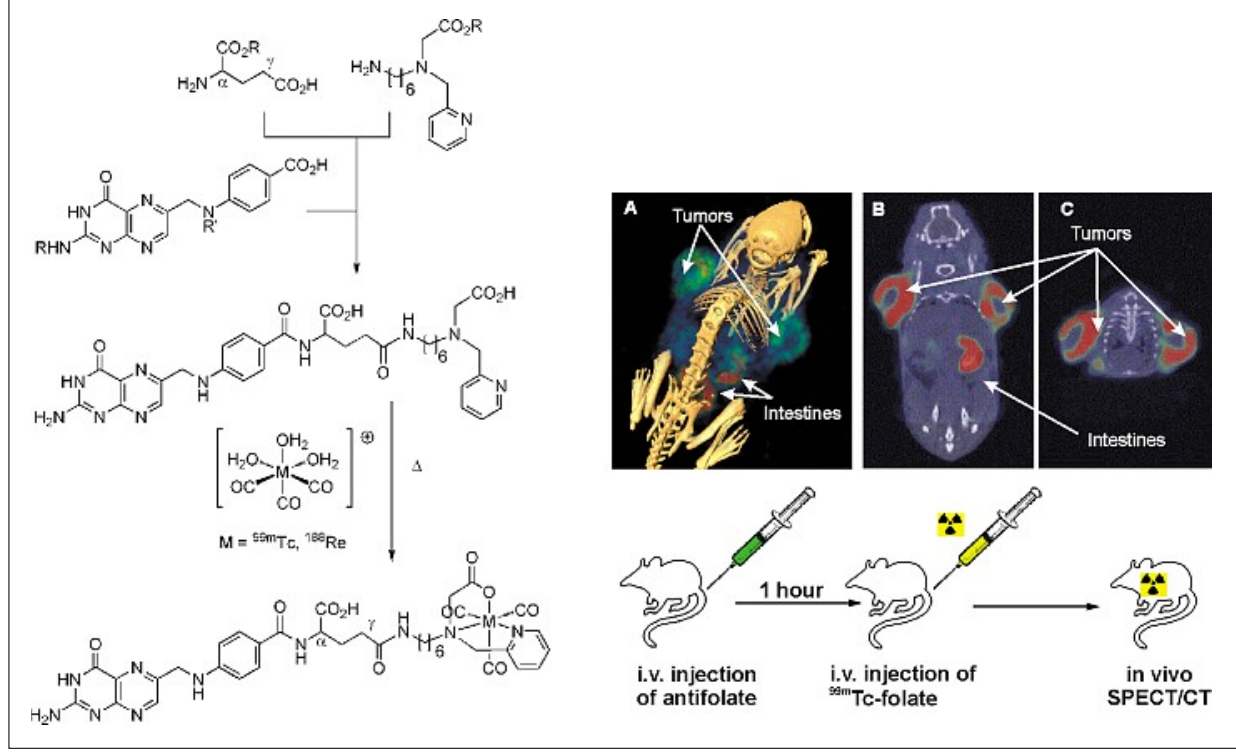

Fig. 5. (left) Example of the site-specific functionalization and radiolabeling of a novel $\gamma$-radiofolate labeled with the organometallic ${ }^{99 \mathrm{~m} T c}(\mathrm{CO})_{3}$ - and ${ }^{188} \mathrm{Re}(\mathrm{CO})_{3}$-core. (right) Whole mouse SPECT/CT of a mouse bearing KB-cell tumors on the right and the left shoulders pre-injected with the antifolate

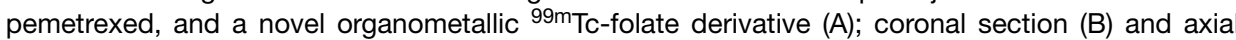
section at the level of the tumors $(C)$. The SPECT studies revealed virtually no radioactivity in the radiation sensitive kidneys. Furthermore, an inhomogeneous distribution of the radiofolate in the tumor xenografts could be detected in a non-invasive manner.
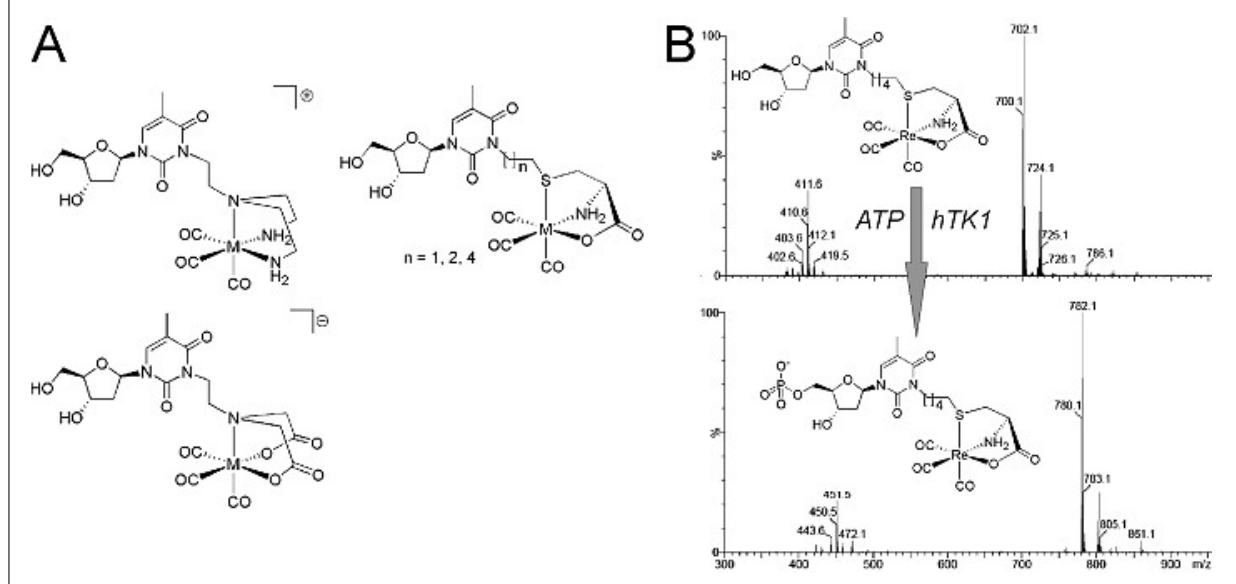

Fig. 6. Structure of N(3)-functionalized and (radio)labeled thymidine complexes for potential use as cell proliferation marker and LC/MS analysis of the phosphorylation of one of the organometallic Rethymidine complex by $\mathrm{hTK} 1$ in presence of ATP

labeled thymidine and uridine derivatives. Thymidine (dT) and thymidine analogs like ${ }^{11} \mathrm{C}$-methyl-thymidine or ${ }^{18} \mathrm{~F}$-fluoro-deoxythymidine ( $\left.{ }^{18} \mathrm{~F}-\mathrm{FLT}\right)$ are already clinically used as proliferation markers. ${ }^{[44,45]}$ Again, for routine application it would be highly desirable to have Tc-99m labeled surrogates. An important feature of nucleoside metabolism is the rapid intracellular phosphorylation of nucleosides to nucleotides, which results in the 'trapping' of nucleotides inside cells. This phenomenon leads to amplification of the radioactive signal in rapidly proliferating cells. Since hTK 1 has a narrow substrate specificity, modifications of the lead structure with bulky substituent can easily lead to compounds with no substrate activity. This might be the reason why several attempts to develop (radio)metallabeled thymidine complexes (e.g. radiolabeled with Tc-99m, Ga-68 and In-111) were unsuccessful.[28,29] We hypothesized that $\mathrm{N}(3)$-functionalized dT (radio)labeled with the smaller $\mathrm{M}(\mathrm{CO})_{3}{ }^{+}$-core are more likely to be accepted as substrates of hTK1. For this purpose dT was derivatized at position N(3) with different tridentate metal chelating systems (giving rise to cationic, neutral and anionic complexes) and tethering groups of different lengths (Fig. 6A). ${ }^{46]}$ To our delight, we found that all these organometallic products were substrates for hTK1 (Fig. 6B). The rate of phosphorylation was dependent on the overall charge of the complex following the rule: neutral $\geq$ anionic $>$ cationic. We could also detect

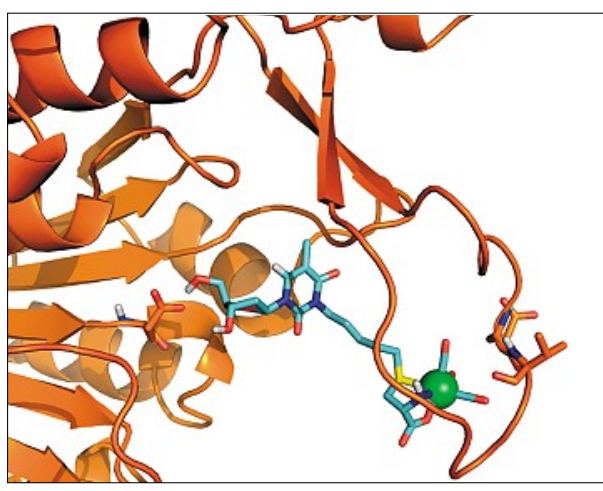

Fig. 7. Position of a neutral, organometallic Tc/ $\operatorname{Re}(\mathrm{CO})_{3}$-thymidine complex (metal in green) in the active site of $\mathrm{hTK} 1$

monophosphorylated rhenium complexes in cell lysates of HT29 cancer cells via mass spectroscopy. ${ }^{[47]}$

MD calculation studies performed with selected organometallic N(3)-functionalized dT derivatives revealed that the base of the dT moiety is stably located in the enzyme's active site forming close contact between Glu98 and H(5') during the entire simulation (Fig. 7) ${ }^{[47]}$ In addition, the tricarbonyl moieties displayed contacts with the two consecutive glycine residues 176 and 177 .

In vitro and in silico experiments performed so far have provided strong evidence that small Tc/Re-labeled thymidine derivatives are:

i) Accepted as substrates of hTK 1 and

ii) Able to penetrate the cell membrane and are intracellularly phosphorylated, when the corresponding labeling core possesses the appropriate size and other important structural and physico-chemical features. ${ }^{[47]}$

The present example also underlines the important role of the metal core and complex for success or failure of a potential novel radiopharmaceutical. Currently, several of our Tc-99m-complexes are subject to further in vitro and in vivo evaluation in order to assess their full potential as cell proliferation markers.

\section{Tumor Targeting with Tc-99m/ Re-188-radiolabled Peptides}

Natural peptides regulate a large variety of physiological functions in the human body. They can act as hormones, neurotransmitters, neuromodulators and growth factors. Moreover, it is also well documented that peptides play a role in pathological conditions. Such peptides usually show high affinity for their corresponding receptors. Consequently small peptide-based radioconjugates have attracted an enormous interest. ${ }^{[48-50]}$ However, small peptides generally reveal a short biological half-life due to a rapid degradation by endogenous peptidases and proteases. After radiolabeling, this 
can lead to deleterious biodistribution of the radioactivity in normal, healthy tissue and/ or low tumor uptake. Thus, apart from stable incorporation of the radionuclide into the peptide, metabolic stabilization of the peptides with chemical methods is crucial for the development of novel radiopharmaceuticals. Stabilization can be achieved by endcapping, substitution of peptide bonds by other chemical bonds, use of $\mathrm{D}$ - or $\beta$-amino acids, or cyclization. The introduction of hydrophilic and/or lipophilic amino acids or spacer entities can modify the rate and the route of excretion without altering binding properties.

The development of a novel, Tc/Re-labeled neurotensin (NT; a 13-amino acid peptide) is an excellent example of the abovementioned strategy. Overexpression of NT receptors has been described in different human tumors. ${ }^{[51]}$ Since NT is rapidly degraded in vivo we prepared several stabilized analogs and tested them in vitro and in vivo after radiolabeling with ${ }^{99 \mathrm{~m}} \mathrm{Tc}(\mathrm{CO})_{3}$. Step-by-step stabilization was achieved via reduction of the amino acid sequence to the minimal sequence necessary for receptor binding (amino acids 8-13), exchange of natural by non-natural amino acids, and reduction or methylation of amidic bonds increased the plasma stability of the peptide dramatically (from 5 min to 28 days) without dramatically compromising the affinity for the NT-receptor (Table). ${ }^{[52-54]}$ Modifications of the three cleavage bonds resulted in the optimal analog NT-XIX. ${ }^{[55]}$ Although affinity to NT receptors was slightly reduced in the case of derivative NT-XIX, the in vivo tumor uptake was retained and both kidney and liver uptakes were significantly reduced. The stabilized NT analogs NT-XII and NT-XIX have also been radiolabeled with ${ }^{188} \operatorname{Re}(\mathrm{CO})_{3}$. It could be demonstrated that both optimized NT analogs significantly delayed growth of HT29 tumor xenografts in mice without significant side effects (Fig. 8).
Table. Amino acid sequence of NT(8-13) and NT-analogs suitable for Tc/Re-labeling (Receptor binding sequence in bold. Arrows indicate metabolic cleavage sites) ${ }^{\mathrm{a}}$

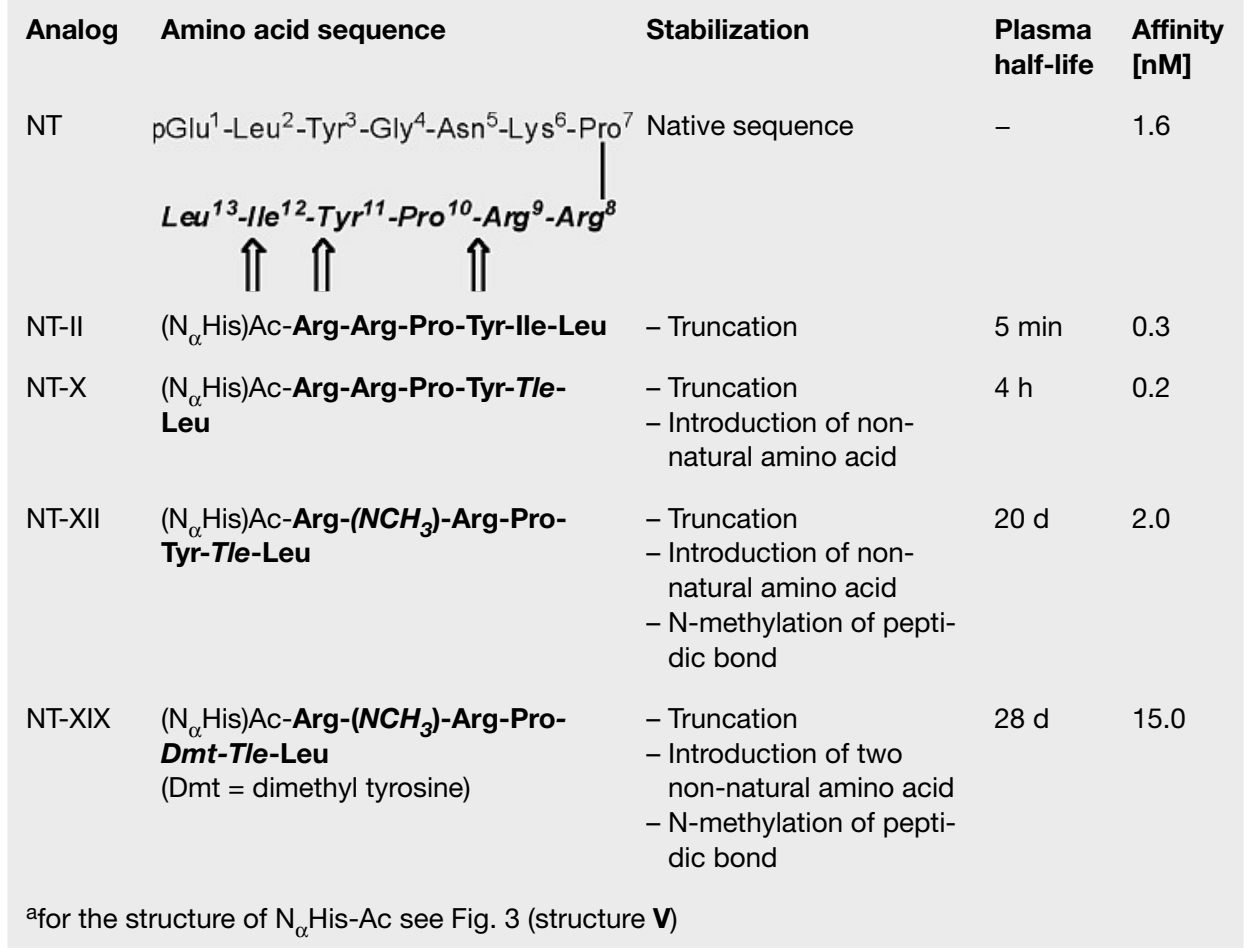

In a first clinical study with 99mTc-NT-XI the tumor of a patient with ductal pancreatic adenocarcinomas could be detected.[56]

\section{Present Trends and Future Perspectives: A Critical, yet Optimistic Assessment}

Novel metal cores of Tc/Re are currently being exploited for potential radiopharmaceutical use. Exchange of one $\mathrm{CO}$ ligand in $\left[\mathrm{M}(\mathrm{CO})_{3}\right]^{+}$by an isolobal $\mathrm{NO}^{+}$results in the formation of a mixed carbonyl-nitrosyl species $\left[\mathrm{M}(\mathrm{CO})_{2}(\mathrm{NO})\right]^{2+} \cdot{ }^{[57-59]}$ This novel core possesses more enhanced binding affinities to anionic chelators, while retaining positive features with respect to size and stability of the isoelectronic tricarbonyl core (Fig. 9). An entirely different approach has been recently proposed by the Alberto group; in a further attempt to reduce the size of technetium complexes they produced technetium(VII) complexes with a trioxotechnetate, $\left[\mathrm{TcO}_{3}\right]^{+}$-core (Fig. 9). [61] The synthesis of both mixed nitrosylcarbonyl and trioxo complexes is currently still challenging and not yet suitable for routine radiopharmaceutical preparations. However, the potential advantages, which

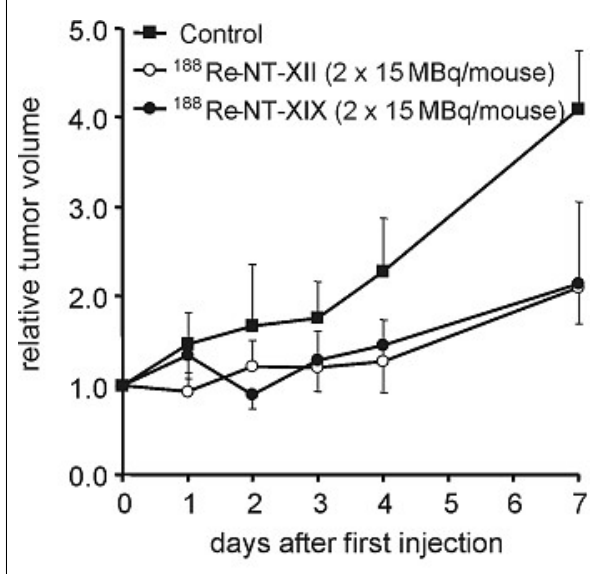

Fig. 8. Therapeutic efficacy of Re-188-labeled neurotensin analogs NT-XII and NT-XIX injected i.v. at day 0 and 2 in mice with HT29 xenografts

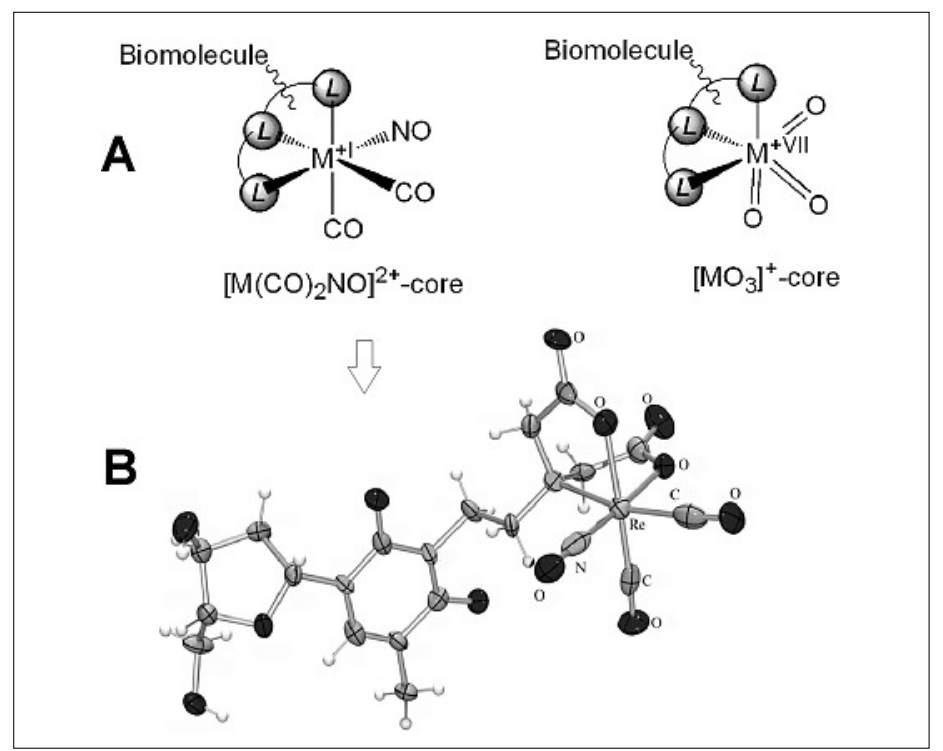

Fig. 9. A: General structure of novel Tc/ Re-cores currently under development for potential use in radiopharmacy. B: X-ray structure of a neutral iminodiacetic acid functionalized thymidine derivative labeled with the $\left[\mathrm{Re}(\mathrm{CO})_{2} \mathrm{NO}^{2+}{ }^{2+}\right.$-core. ${ }^{[60]}$ 
arise from such inert and small complexes, clearly warrant further investigations.

Despite the enthusiasm about the recent chemical and radiopharmaceutical progress made in order to produce novel Tc-99m and Re-188-radiopharmaceuticals, one has to critically acknowledge, that since 1999 no new Tc- $99 \mathrm{~m} / \mathrm{Re}-188$-tracer has been brought to FDA approval.[62] The reasons for this rather disappointing fact are often not of scientific nature and parallel the problems of other new, diagnostic drugs (the risk of insufficient return of investment and increasing regulatory hurdles). In addition, the general trend towards more specific radiopharmaceuticals, which are applicable only for a limited patient population, will accentuate this problem in the future. Thus, it might be worthwhile to seek alternative applications and research areas for SPECT tracers.

An important field, which is almost completely dominated by PET, is drug development using specific biomarkers or radioactive PET-analogs of promising drug candidates. Clearly the 'organic' isotopes ${ }^{11} \mathrm{C}$ or ${ }^{18} \mathrm{~F}$ have structural advantages over the larger $\mathrm{Tc} / \mathrm{Re}$ metal complexes when incorporated into a given lead structure. However, PET is a very expensive endeavor. In addition, the chemical methods for ${ }^{11} \mathrm{C}$ - or ${ }^{18} \mathrm{~F}$-labeling are rarely quantitative and easy to perform. The short half-life of these isotopes largely precludes their use with biomolecules with a long biological half-life such as proteins. The problems responsible for the lack of interest of Tc-99m SPECT tracers in the drug development process are:

i) Preparation of appropriate metal chelators generally requires multi-step syntheses.

ii) Incorporation of the ligand systems into biomolecules often lacks efficiency and is difficult due to cross-reactivity with other functional groups present in the biomolecule.

iii) The metal center itself can cross react with functional groups of the biomolecule.

We recently recognized that 'click' chemistry[63] (the copper-(I)-catalyzed $[3+2]$ cycloaddition of terminal alkynes and azides) could help solve the problems mentioned above. Click chemistry is particularly valuable because it is efficient, selective and devoid of side reactions. ${ }^{[64]}$ The mild reaction conditions of the cycloaddition are well suited for the modification of a wide variety of (bio)molecules, into which the required azide and alkyne functionalities can be incorporated by standard synthetic transformations or biochemical methods. ${ }^{[65]}$ The features of click chemistry parallel the requirements of an innovative functionalization strategy for biomolecules. We have shown that click

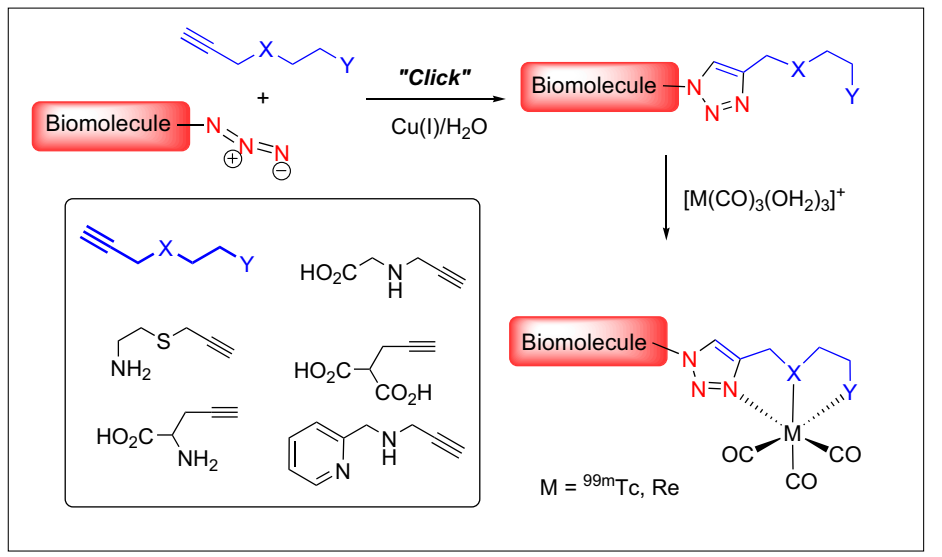

Fig. 10. Schematic drawing of the modular 'click-to-chelate' approach: Synthesis of the 1,2,3-triazole comprising metal chelates and their incorporation into a biomolecule is achieved simultaneously under mild and aqueous conditions. The reaction can be performed without any protecting groups on the chelate of the biomolecule.

chemistry enables the facile synthesis of efficient bifunctional ligands in which 1,4-disubstituted triazoles form an integral part of the metal chelating system (useful for the $\mathrm{M}(\mathrm{CO})_{3}$-core but presumably also for other Tc/Re-cores). ${ }^{[66]}$ Application of click chemistry both simplifies the preparation of chelators and facilitates their incorporation into (bio)molecules. Metal labeling of these chelators and bioconjugates thereof is efficient and gives rise to organometallic Tc/Re-complexes that are stable in vitro and in vivo. The backbone of the chelators and thus the overall charge and/or the lipophilicity etc. can be readily modulated using different ligand building blocks (Fig. 10). ${ }^{[67]}$ Given the fact that numerous clickable organic and biological compounds are currently being developed for a wide variety of purposes, the 'clickto-chelate' approach is most attractive for radiopharmacy. More importantly, the versatility and simplicity of this method could make Tc-99m-SPECT an attractive alternative to PET as the first choice for assessment of the general pharmacological profile of new compounds.

\section{Conclusion}

Tc-99m is the mainstay of routine diagnostic nuclear medicine and it is unlikely that PET will become the sole modality in nuclear medicine in the future. PET has many attractive features, and for quantitative studies it is clearly superior to SPECT. However, in terms of logistics, availability, access and cost, single-photon emitting radiopharmaceuticals have undeniable advantages. To make Tc-99m-tracers attractive (once again), the functionalization and radiolabeling chemistry has to be further simplified and made more widely applicable. In this respect, the $\left[\mathrm{M}(\mathrm{CO})_{3}\right]^{+}$-core has clearly made a significant contribution and new emerging methodologies will facilitate new applications. At the same time, pre-clinical, small animal SPECT/CT imaging has made tremendous progress. Several robust and user-friendly SPECT scanner systems with sub-millimeter resolution and high sensitivity have become commercial available at a fraction of the price of comparable PET scanners. It is likely that the performance of clinical SPECT scanners will improve further in the future. On the other hand, it should be kept in mind that with Re-186/188 there is always a therapeutic option/analog for a successfully developed Tc-99m radiotracer. There is no such opportunity for $\mathrm{PET}$ radionuclides such as ${ }^{11} \mathrm{C}$ and ${ }^{18} \mathrm{~F}$. The encouraging results presented in the recent literature make us believe that there are still a lot of opportunities for Tc$99 \mathrm{~m}$ and $\mathrm{Re}-186 / 188$ in radiopharmaceutical application and as preclinical research tools.

\section{Acknowledgments}

This work was supported by MallinckrodtTyco, Nihon Medi-Physics CO. and MerckEprova.

Received: August 27, 2007

[1] American Cancer Association: http:// www.cancer.org, 2007.

[2] J. M. Vose, Oncologist 2004, 9, 160.

[3] W. A. Volkert, T. J. Hoffman, Chem. Rev. 1999, 99, 2269.

[4] K. Lei, M. Rusckowski, F. Chang, T. Qu, G. Mardirossian, D. J. Hnatowich, Nucl. Med. Biol. 1996, 23, 917.

[5] S. R. Karra, R. Schibli, H. Gali, K. V. Katti, T. J. Hoffman, C. Higginbotham, G. L. Sieckman, W. A. Volkert, Bioconjugate Chem. 1999, 10, 254.

[6] J. A. Barrett, A. C. Crocker, D. J. Damphousse, S. J. Heminway, S. Liu, D. S. Edwards, J. L. Lazewatsky, M. Kagan, T. J. Mazaika, T. R. Carroll, Bioconjugate Chem. 1997, 8, 155 .

[7] C. Bolzati, A. Caporale, S. Agostini, D. Carta, C. Cavazza-Ceccato, F. Refosco, F. Tisato, E. Schievano, G. Bandoli, Nucl. Med. Biol. 2007, 34, 511.

[8] A. Egli, R. Alberto, L. Tannahill, R. Schibli, U. Abram, A. Schaffland, R. Waibel, D. Tourwe, L. Jeannin, K. Iterbeke, P. A. Schubiger, J. Nucl. Med. 1999, 40, 1913.

[9] W. A. Volkert, S. Jurisson, in 'Technetium and Rhenium', Eds. K. Yoshihara, T. Om- 
ori, Springer Verlag: Berlin, Heidelberg, New York, 1996, Vol. 176, pp 123.

[10] S. Jurisson, D. Berning, W. Jia, D. S. Ma, Chem. Rev. 1993, 93, 1137.

[11] The functionalized biomolecules are added in excess in order to achieve high labeling yields with Tc-99m or Re-188. For routine (clinical) application radiolabeled and unlabelled products are not separated before application.

[12] E. von Guggenberg, M. Behe, T. M. Behr, M. Saurer, T. Seppi, C. Decristoforo, Bioconjugate Chem. 2004, 15, 864.

[13] Y. M. Zhang, N. Liu, Z. H. Zhu, M. Rusckowski, D. J. Hnatowich, Eur. J. Nucl. Med. 2000, 27, 1700.

[14] C. Decristoforo, S. J. Mather, Nucl. Med. Biol. 1999, 26, 389.

[15] C. Bolzati, C. Benini, C. Cavazza-Ceccato, E. Malago, S. Agostini, F. Tisato, F. Refosco, B. Bandoli, Bioconjugate Chem. 2006, 17, 419 .

[16] C. Bolzati, A. Mahmood, E. Malago, L. Uccelli, A. Boschi, A. G. Jones, F. Refosco, A. Duatti, F. Tisato, Bioconjugate Chem. 2003, 14, 1231.

[17] A. Boschi, L. Uccelli, A. Duatti, C. Bolzati, F. Refosco, F. Tisato, R. Romagnoli, P. G. Baraldi, K. Varani, P. A. Borea, Bioconjugate Chem. 2003, 14, 1279.

[18] R. Alberto, R. Schibli, A. Egli, A. P. Schubiger, U. Abram, T. A. Kaden, J. Am. Chem. Soc. 1998, 120, 7987.

[19] R. Schibli, R. Schwarzbach, R. Alberto, K. Ortner, H. Schmalle, C. Dumas, A. Egli, A. P. Schubiger, Bioconjugate Chem. 2002, 13, 750 .

[20] J. Wald, R. Alberto, K. Ortner, L. Candreia, Angew. Chem., Int. Ed. 2001, 40, 3062.

[21] R. Schibli, R. La Bella, R. Alberto, E. Garcia-Garayoa, K. Ortner, U. Abram, P. A. Schubiger, Bioconjugate Chem. 2000, 11,345 .

[22] S. Seifert, J. U. Kunstler, A. Gupta, H. Funke, T. Reich, H. E. Pietzsch, R. Alberto, B. Johannsen, Inorg. Chim. Acta 2001, $322,79$.

[23] C. Müller, P. A. Schubiger, R. Schibli, Bioconjugate Chem. 2006, 17, 797.

[24] D. R. van Staveren, R. Waibel, S. Mundwiler, P. A. Schubiger, R. Alberto, J. Organomet. Chem. 2004, 689, 4803.

[25] C. P. Leamon, M. A. Parker, I. R. Vlahov, L. C. Xu, J. A. Reddy, M. Vetzel, N. Douglas, Bioconjugate Chem. 2002, 13, 1200.

[26] M. Stichelberger, D. Desbouis, V. Spiwok, L. Scapozza, A. P. Schubiger, R. Schibli, J. Organomet. Chem. 2007, 692, 1255.

[27] D. Desbouis, A. P. Schubiger, R. Schibli, J. Organomet. Chem. 2007, 692, 1340.

[28] M. Schmid, B. Neumaier, A. T. J. Vogg, K. Wczasek, C. Friesen, F. M. Mottaghy, A. K. Buck, S. N. Reske, Nucl. Med. Biol. 2006, 33, 359 .

[29] S. Celen, T. J. De Groot, J. Balzarini, K. Vunckx, C. Terwinghe, P. Vermaelen, L. Van Berckelaer, H. Vanbilloen, J. Nuyts, L. Mortelmans, A. Verbruggen,
G. Bormans, Nucl. Med. Biol. 2007, 34 , 283.

[30] R. Schibli, C. Dumas, J. Petrig, L. Spadola, L. Scapozza, E. Garcia-Garayoa, P. A. Schubiger, Bioconjugate Chem. 2005, 16 , 105.

[31] D. J. Yang, C.-G. Kim, N. R. Schechter, A. Azhdarinia, D. F. Yu, C.-S. Oh, J. L. Bryant, J.-J. Won, E. E. Kim, D. A. Podoloff, Radiology 2003, 226, 465.

[32] Y. Liu, J. K. Pak, P. Schmutz, M. Bauwens, J. Mertens, H. H. Knight Castro, R. Alberto, J. Am. Chem. Soc. 2006, 128 15996.

[33] P. Garin-Chesa, I. Campbell, P. E. Saigo, J. L. Lewis, L. J. Old, W. J. Rettig, Am. J. Pathol. 1993, 142, 557.

[34] N. Parker, M. J. Turk, E. Westrick, J. D Lewis, P. S. Low, C. P. Leamon, Anal. Biochem. 2005, 338, 284.

[35] C. P. Leamon, P. S. Low, Drug Discovery Today 2001, 6, 44

[36] J. A. Reddy, L. C. Xu, N. Parker, M. Vetzel, C. P. Leamon, J. Nucl. Med. 2004, 45 , 857.

[37] C. Müller, A. Hohn, P. A. Schubiger, R. Schibli, Eur. J. Nucl. Med. Mol. Imaging 2006, 33, 1007.

[38] C. Müller, A. P. Schubiger, R. Schibli, Nucl. Med. Biol. 2007, in press.

[39] C. Müller, M. Brühlmeier, A. P. Schubiger, R. Schibli, J. Nucl. Med. 2006, 47, 2057.

[40] T. Yusa, Y. Yamaguchi, H. Ohwada, Y. Hayashi, N. Kuroiwa, T. Morita, M. Asanagi, Y. Moriyama, S. Fujimura, Cancer Res. 1988, 48, 5001 .

[41] K. L. O'Neill, M. Hoper, G. W. Odlingsmee, J. Natl. Cancer Inst. 1992, 84, 1825.

[42] M. Hengstschläger, O. Pusch, E. Hengstschläger-Ottnad, P. F. Ambros, G. Bernaschek, E. Wawra, DNA Cell Biol. 1996, 15 , 41.

[43] B. Munchpetersen, G. Tyrsted, L. Cloos, R. A. Beck, K. Eger, Biochim. Biophys. Acta-Protein Struct. Molec. Enzym. 1995, 1250,158

[44] O. Gardelle, U. Roelcke, P. Vontobel, N. E A. Crompton, I. Guenther, P. Blauenstein, A. P. Schubiger, H. Blattmann, J. E. Ryser, K. L. Leenders, B. Kaser-Hotz, Nucl. Med. Biol. 2001, 28, 51.

[45] I. Buchmann, A. T. J. Vogg, G. Glatting, S. Schultheiss, P. Moller, F. Leithauser M. Schulte, W. Gfrorer, J. Kotzerke, S. N. Reske, Cancer Biother. Radiopharm. 2003, 18, 327

[46] T. Anguelov, D. Desbouis, R. Schibli, in 'Technetium, Rhenium and other metals in Chemistry and Nuclear Medicine 7', Ed. U. Mazzi, SGE Edioriali: Padua, 2006, Vol. 7, pp 131

[47] D. Desbouis, V. Spiwok, R. Schibli, 2007, unpublished data.

[48] A. Heppeler, S. Froidevaux, A. N. Eberle, H. R. Maecke, Curr. Med. Chem. 2000, 7 , 971.

[49] S. Liu, D. S. Edwards, Chem. Rev. 1999, 99, 2235.
[50] M. Gotthardt, O. C. Boerman, T. M. Behr, M. Behe, W. J. G. Oyen, Curr. Pharm. Design 2004, 10, 2951.

[51] J. C. Reubi, B. Waser, Eur. J. Nucl. Med. Mol. Imaging 2003, 30, 781.

[52] E. Garcia-Garayoa, L. Allemann-Tannahill, P. Blauenstein, M. Willmann, N. Carrel-Remy, D. Tourwe, K. Iterbeke, P. Conrath, P. A. Schubiger, Nucl. Med. Biol. 2001, 28, 75 .

[53] E. Garcia-Garayoa, P. Blauenstein, M Bruehlmeier, A. Blanc, K. Iterbeke, P. Conrath, D. Tourwe, P. A. Schubiger, $J$. Nucl. Med. 2002, 43, 374

[54] M. Brühlmeier, E. G. Garayoa, A. Blanc, B. Holzer, S. Gergely, D. Tourwe, P. A. Schubiger, P. Blauenstein, Nucl. Med. Biol. 2002, 29, 321.

[55] E. Garcia-Garayoa, V. Maes, P. Blauenstein, A. Blanc, A. Hohn, D. Tourwe, P. A. Schubiger, Nucl. Med. Biol. 2006, 33, 495.

[56] F. Buchegger, F. Bonvin, M. Kosinski, A. O. Schaffland, J. Prior, J. C. Reubi, P. Blauenstein, D. Tourwe, E. G. Garayoa, A. B. Delaloye, J. Nucl. Med. 2003, 44, 1649

[57] D. Rattat, P. A. Schubiger, H. G. Berke, H. Schmalle, R. Alberto, Cancer Biother. Radiopharm. 2001, 16, 339.

[58] R. Schibli, N. Marti, P. Maurer, B. Spingler, M. L. Lehaire, V. Gramlich, C. L. Barnes, Inorg. Chem. 2005, 44, 683.

[59] M. L. Lehaire, P. V. Grundler, S. Steinhauser, N. Marti, L. Helm, K. Hegetschweiler, R. Schibli, A. E. Merbach, Inorg. Chem. 2006, $45,4199$.

[60] H. Struthers, U. Abram, S. Abram, A. Hagenbach, R. Schibli, 2007, manuscript in preparation.

[61] Y. Tooyama, H. Braband, U. Abram, R. Alberto, in 'Technetium, Rhenium and other metals in Chemistry and Nuclear Medicine 7', Ed. U. Mazzi, SDG Editoriali: Padua, 2006, Vol. 7, pp 159.

[62] ${ }^{99 m} \mathrm{Tc}$-depreotide $\left(\right.$ Neotec $\left.^{\circledR}\right)$ for the detection of somatostatin receptor-positive tumors was approved in 1999.

[63] A. K. F. P. Wu, A. K. Nugent, C. J. Hawker, A. Scheel, B. Voit, J. Pyun, J. M. J. Fréchet, K. B. Sharpless, V. V. Fokin, Angew. Chem., Int. Edit. 2004, 43, 3928.

[64] H. C. Kolb, K. B. Sharpless, Drug Discovery Today 2003, 8,1128 .

[65] J. A. Prescher, C. R. Bertozzi, Nature Chemical Biology 2005, 1, 13.

[66] T. L. Mindt, H. Struthers, L. Brans, T. Anguelov, C. Schweinsberg, V. Maes, D. Tourwe, R. Schibli, J. Am. Chem. Soc. 2006, 128, 15096.

[67] H. Struthers, R. Schibli, J. Label. Compd. Radiopharm. 2006, 50, S254. 